\title{
Effect of dietary restraint and mood state on attentional processing of food cues
}

Citation for published version (APA):

Donofry, S. D., van Zoest, W., Moonen, A., Sacchetti, S., Nederkoorn, C., \& Roefs, A. (2019). Effect of dietary restraint and mood state on attentional processing of food cues. Journal of Behavior Therapy and Experimental Psychiatry, 62, 117-124. https://doi.org/10.1016/j.jbtep.2018.10.002

Document status and date:

Published: 01/03/2019

DOI:

10.1016/j.jbtep.2018.10.002

Document Version:

Publisher's PDF, also known as Version of record

Document license:

Taverne

Please check the document version of this publication:

- A submitted manuscript is the version of the article upon submission and before peer-review. There can be important differences between the submitted version and the official published version of record.

People interested in the research are advised to contact the author for the final version of the publication, or visit the DOI to the publisher's website.

- The final author version and the galley proof are versions of the publication after peer review.

- The final published version features the final layout of the paper including the volume, issue and page numbers.

Link to publication

\footnotetext{
General rights rights.

- You may freely distribute the URL identifying the publication in the public portal. please follow below link for the End User Agreement:

www.umlib.nl/taverne-license

Take down policy

If you believe that this document breaches copyright please contact us at:

repository@maastrichtuniversity.nl

providing details and we will investigate your claim.
}

Copyright and moral rights for the publications made accessible in the public portal are retained by the authors and/or other copyright owners and it is a condition of accessing publications that users recognise and abide by the legal requirements associated with these

- Users may download and print one copy of any publication from the public portal for the purpose of private study or research.

- You may not further distribute the material or use it for any profit-making activity or commercial gain

If the publication is distributed under the terms of Article $25 \mathrm{fa}$ of the Dutch Copyright Act, indicated by the "Taverne" license above, 


\title{
Effect of dietary restraint and mood state on attentional processing of food cues
}

\author{
Shannon D. Donofry ${ }^{\mathrm{a}, *}$, Wieske van Zoest ${ }^{\mathrm{b}}$, Andrea Moonen ${ }^{\mathrm{c}}$, Sofia Sacchetti ${ }^{\mathrm{c}}$, \\ Chantal Nederkoorn ${ }^{\mathrm{c}}$, Anne Roefs ${ }^{\mathrm{c}}$

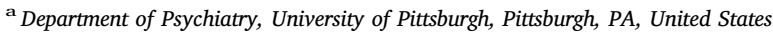 \\ ${ }^{\mathrm{b}}$ Center for Mind/Brain Sciences, University of Trento, Trento, Italy \\ ${ }^{\mathrm{c}}$ Faculty of Psychology and Neuroscience, Maastricht University, Maastricht, the Netherlands
}

\section{A R T I C L E I N F O}

\section{Keywords:}

Dietary restraint

Attention bias

Negative mood

Food cues

\begin{abstract}
A B S T R A C T
Background and objectives: Research linking dietary restraint to attentional bias toward food cues has been equivocal, suggesting that dietary restraint may only influence attentional processing of food in certain contexts. The present study examined whether negative mood strengthens the association between dietary restraint and attention bias for food.

Methods: Healthy female participants were randomized to either a neutral $(n=47)$ or negative $\operatorname{mood}(n=49)$ induction. Participants then completed a visual search task featuring targets displayed adjacent to pictures of palatable food, musical instruments, or non-instrument filler objects. Attention bias for food was operationalized as shorter response latency when the target appeared adjacent to palatable food as compared to musical instruments. Attention bias was examined in a 2 (mood condition) $\times 2$ (picture: food vs. instrument) $\times 2$ (target location: match vs. mismatch) repeated measures ANCOVA, with dietary restraint as a continuous covariate and response latency as the dependent variable.

Results: Though there was no evidence of an interaction between mood condition and dietary restraint, mood had an influence on attention allocation. Contrary to study hypotheses, individuals in the neutral mood condition, but not those in the negative mood condition, responded in a manner indicative of bias toward food. Limitations: Additional research is necessary to validate the experimental task used in the present study to assess food-specific attentional bias.

Conclusions: Neutral mood may be associated with enhanced processing of palatable food cues. Critically, results do not support the hypothesized link between negative mood and attention bias for food.
\end{abstract}

\section{Background}

Maintenance of a healthy weight is challenging given the abundance of highly palatable calorie dense foods and the ubiquity of food and eating cues (Brownell \& Horgen, 2004; Harris, Bargh, \& Brownell, 2009). Paradoxically, chronic attempts to exert dietary restraint when confronted with palatable food have been shown to predict increased snacking (Papies \& Hamstra, 2010), binge eating (Field, Austin, Taylor, Malspeis, Rosner et al., 2003) and weight gain (Lowe et al., 2006; Stice, Cameron, Killen, Hayward, \& Taylor, 1999). The paradoxical effect of dietary restraint on eating and weight is thought to arise when contextual factors such as exposure to palatable food cues shift motivational processes away from the goal of being healthy to the immediate goal of experiencing the pleasure of eating, with the motivation to achieve this immediate goal being heightened among chronic dieters (Stroebe, Van Koningsbruggen, Papies, \& Aarts, 2013). This suggests that preoccupation with eating and weight may enhance rather than diminish processing of food cues, thus increasing vulnerability for failures in dietary self-regulation.

Consistent with this hypothesis, several studies have demonstrated that individuals characterized as restrained eaters exhibit attentional biases for food cues as measured by visual search, flanker, and eyetracking tasks (Forestell, Lau, Gyurovski, Dickter, \& Haque, 2012; Hollitt, Kemps, Tiggemann, Smeets, \& Mills, 2010; Meule, Vögele, \& Kübler, 2012; Neimeijer, de Jong, \& Roefs, 2013). For instance, restrained eaters more quickly detected food items in an array of neutral distractor items than they were able to detect neutral items in a neutral array (Hollitt et al., 2010). Moreover, biased attention to food has been

\footnotetext{
* Corresponding author. Department of Psychiatry, University of Pittsburgh, 3811 O'Hara Street, Pittsburgh, PA, 15213, United States.

E-mail addresses: Sdd14@pitt.edu, Shannon.donofry@gmail.com (S.D. Donofry).
} 
shown to predict snacking behavior (Werthmann, Field, Roefs, Nederkoorn, \& Jansen, 2014a,b) and weight gain (Yokum, Ng, \& Stice, 2011). However, it is important to note that other studies have failed to find evidence of attentional biases towards food in restrained eaters (Ahern, Field, Yokum, Bohon, \& Stice, 2010; Boon, Vogelzang, \& Jansen, 2000; Werthmann et al., 2013; Wilson \& Wallis, 2013), or documented attentional avoidance of, rather than orientation toward, food cues (Werthmann, Jansen, \& Roefs, 2015; Veenstra, de Jong, Koster, \& Roefs, 2010). Importantly, these null or unexpected associations between dietary restraint and attentional processing of food cues were documented using a variety of tasks (e.g., visual probe, eyetracking), as well as a variety of dietary restraint measures each capturing slightly different aspects of this construct (e.g., disinhibited eating vs. successful calorie restriction). Therefore, failure to observe a relationship between dietary restraint and attentional bias toward food cannot be attributed to the manner in which either attentional bias or dietary restraint were operationalized. Further, it seems that the findings reported by Hollitt et al. (2010) were primarily driven by slowed responding on non-food trials rather than by faster responding on food trials among individuals high in dietary restraint, contrary to what would be expected if indeed dietary restraint was associated with attentional bias toward food. These inconsistencies suggest that the relationship between dietary restraint and attentional processing of food cues is moderated by other social, cognitive, or affective factors that either promote or impair self-regulation. Examining these moderating variables may help to identify mechanisms underlying failures in dietary self-regulation.

Negative affect is one of the most robust predictors of failures in self-regulation, and has been hypothesized to promote shifting of attentional and cognitive resources from long-term goals to the immediate goal of alleviating negative mood (Heatherton \& Wagner, 2011). Negative affect promotes attentional processing of food cues (Hepworth, Mogg, Brignell, \& Bradley, 2010), and reward value of food is heightened during negative affective states (Wagner, Boswell, Kelley, \& Heatherton, 2012; Willner et al., 1998). Further, neural responses to food cues are moderated by negative affect in key regions of the brain participating in learning, motivation, and emotion regulation (e.g., Bohon \& Stice, 2012; Bohon, Stice, \& Spoor, 2009). Negative affect can also precipitate episodes of binge eating (Crosby et al., 2009; HaedtMatt \& Keel, 2011). For instance, restrained eaters have been shown to consume more calories following the induction of a negative mood state compared to restrained eaters in a neutral mood state and unrestrained eaters in either mood state (Cardi, Leppanen, \& Treasure, 2015; Chua, Touyz, \& Hill, 2004; Fay \& Finlayson, 2011; Stroebe et al., 2013). A similar pattern has been observed in dieters (Baucom \& Aiken, 1981), and in overweight and obese individuals (Chua et al., 2004; Jansen, Vanreyten, van Balveren, Roefs, \& Nederkoorn, 2008). Therefore, differential responses to food cues may impede efforts to control food intake and weight, particularly during the experience of negative affect. Examining the relationship between attentional processes and negative affect may therefore reveal important risk factors for obesity among chronic dieters.

Although previous experiments have separately assessed the effect of dietary restraint and negative mood on attentional processing of food cues, few studies have investigated both factors simultaneously. Further, those that have done so have not consistently demonstrated a relationship between negative affect and attentional allocation in restrained eaters as compared to those low in dietary restraint, with one study observing heightened attentional bias toward food among restrained eaters in response to induced negative affect (Hepworth et al., 2010), and the other finding no evidence of such a relationship (Werthmann et al., 2014b). Therefore, the goal of the present study was to test whether negative affect facilitates more thorough attentional processing of high calorie foods, particularly among restrained eaters. It was hypothesized that individuals who scored high on dietary restraint would exhibit biased attention to food cues compared to individuals who scored low on dietary restraint, but only for those in a negative mood state.

To test these hypotheses, participants were randomized into either a neutral or a negative mood condition, with those in the negative mood condition undergoing a well-validated mood manipulation (Vuoskoski \& Eerola, 2012). Attention was assessed using a paradigm designed by Devue, Belopolsky, and Theeuwes (2012) adapted for the purposes of measuring food-specific biases in attention. There are several advantages of this task. First, the task features a complex visual array with more objects presented simultaneously, requiring participants to engage in serial visual search in order to identify the target. Second, the stimuli are not predictive of the target response, making the purpose of the task less obvious to participants and reducing the likelihood that responses will be influenced by participants' strategies and intentions. The study hypotheses, methods, and analytical plan were pre-registered with AsPredicted prior to the start of data collection. The pre-registration can be accessed at http://aspredicted.org/y22mk.pdf.

\section{Materials and methods}

\subsection{Participants}

A-priori power analyses were conducted in GPower v. 3.1 using effect sizes from similar investigations (e.g., Hepworth et al., 2010; Werthmann et al., 2014b, 2014a) to estimate the sample size necessary to observe the hypothesized effect. Assuming a small to medium effect size with $80 \%$ power and $\alpha=0.05$, a sample size of 100 would be adequate to detect such an effect. Therefore, 100 healthy females aged 18 to $30\left(M_{\text {age }}=21.13, S D=2.52\right)$ were recruited for participation through advertisements placed in campus buildings at Maastricht University. To minimize the influence of participants' expectations about the purpose of the study on performance, a cover story was provided describing the study as an investigation of music and cognition. Participant selection was limited to women in order to have a homogeneous sample for this initial investigation, and because women have significantly higher rates of dieting and weight concerns compared to men (Anderson \& Bulik, 2004; Davy, Benes, \& Driskell, 2006). Participants were compensated with either a single research credit or $€ 7.50$. All procedures were approved by the local ethics committee, and informed consent was obtained prior to the start of the experiment. If so desired, participants were provided with a Dutch translation of the informed consent document and questionnaires. Well-validated Dutch translations of each questionnaire were used. Participants were given an explanation of the purpose of the study via email after all participants had completed all experimental procedures. This was done to reduce the likelihood that individuals who had already participated would reveal the purpose of the study to others interested in participating.

\subsection{Measures}

\subsubsection{Dietary restraint}

Dietary restraint was assessed using the Restraint Scale (Herman \& Polivy, 1975; Herman, Polivy, Pilner, Threlkeld, \& Munic, 1978), which contains 10 questions assessing how often respondents engage in various behaviors to control their food intake and weight. Items are rated on a 5-point Likert scale ranging from 1 (never) to 5 (very often), with higher scores reflecting greater dietary restraint. Compared to other assessments of dietary restraint (e.g., Dutch Eating Behavior Questionnaire (DBEQ), Van Strien, Frijters, Bergers, \& Defares, 1986), the Restraint Scale captures components of dietary restraint such as disinhibited eating, weight fluctuations, and unsuccessful attempts at weight control more so than successful calorie restriction (Laessle, Tuschl, Kotthaus, \& Pirke, 1989). Contextual factors have been shown to exert a greater influence on eating behavior among individuals who score high on the Restraint Scale (Heatherton, Herman, \& Polivy, 1991), suggesting that the Restraint Scale is more likely than other measures to 
capture individuals whose eating may be influenced by changes in mood. Compared to other measures of dietary restraint, the Restraint Scale has also been associated with impulsivity (Mills, Weinheimer, Polivy, \& Herman, 2018), a trait that predicts disinhibited eating in the presence of highly desired but forbidden foods (Jansen et al., 2009). As such, the Restraint Scale is most relevant to the processes of interest in the present study. Scores on the Restraint Scale are also moderately correlated with other measures of dietary restraint such as the DBEQ ( $r=0.55$; Jansen, Oosterlaan, Merckelbach, \& van den Hout, 1988; Williamson et al., 2007), and the relationship between Restraint Scale scores and disinhibited eating has been shown to be comparable to that of the DBEQ (Jansen et al., 1988). The Restraint Scale exhibited acceptable internal consistency (Cronbach's $\alpha=0.76$ ) in the present sample.

\subsubsection{Depressive symptoms}

Depressive symptoms were measured using the Beck Depression Inventory-II (BDI-II; Beck, Steer, \& Brown, 1996), a well-validated 21item self-report measure. In the present sample, the BDI-II demonstrated good internal consistency (Cronbach's $\alpha=0.85$ ).

\subsubsection{State mood}

Participants were also asked to rate their present mood using a $100 \mathrm{~mm}$ visual analog scale (VAS) ranging from 0 (not sad at all) to 100 (very sad). Mood was measured both before and after the mood manipulation, as well as after 3 mood boosters interspersed throughout the visual search task, yielding a total of five measurements of mood.

\subsubsection{Mood induction}

The present study used the mood induction procedure described by Vuoskoski and Eerola (2012).

Briefly, all participants were instructed to bring approximately 8 min of music that makes them feel happy, and 8 min of music that makes them feel sad. Prior to the start of the experiment, each participant was randomly assigned to either the negative or the neutral mood condition. Participants in the negative mood condition were told to listen carefully to their sad pieces of music and to allow themselves to fully experience the feelings evoked, while writing about a negative personal memory. Participants randomized to the neutral mood condition were instructed to write about their daily commute from home to the university, and the steps they would need to take in order to check a book out of the library to copy a random chapter. While completing this task, participants in the neutral condition listened to the first movement (De l'aube à midi sur la mer; duration $8 \mathrm{~min} 41 \mathrm{~s}$ ) of the orchestral work La mer by Claude Debussy. Previous research has established that this piece of music is perceived as affectively neutral by listeners (Vuoskoski \& Eerola, 2012).

To ensure that the desired mood state was maintained throughout the duration of the attention task, three mood boosters were administered at regular intervals during the task. Mood boosters were administered according to the same procedure as the initial induction, but for a reduced duration of $2 \mathrm{~min}$. At the end of the attention task, participants in both mood conditions underwent a positive mood induction lasting $3 \mathrm{~min}$, during which they were instructed to listen carefully to their happy pieces of music while writing about a positive personal memory.

\subsection{Attention task}

\subsubsection{Stimuli and displays}

Stimuli were presented electronically using the E-Prime 3.0 software (Psychology Software Tools, Pittsburgh, PA). The display consisted of six color images arranged in a circle on a white background. Three categories of stimuli were presented, including two types of critical objects: high calorie food (e.g., pizza) and musical instruments, as well as non-instrument filler objects (e.g., stapler). For each trial, one critical object was presented along with five non-instrument filler objects. Depending on the trial type (food or instrument), images were randomly selected from a directory of 22 high calorie foods, a directory of 22 instruments, and a directory of 60 filler objects. The stimuli belonging to one of the critical object categories (food or musical instruments) were visually matched based on color, size, and object complexity in an effort to ensure that marked visual differences between the critical objects did not influence performance. These judgments were made by the authors prior to the start of the experiment, and these images have been used in previous research on biased attention (Werthmann et al., 2011, 2016). Images were not customized based on participants' food preferences or personal ratings. Surrounding these images were 6 grey circles containing line segments of various orientations $\left(-75^{\circ},-50^{\circ},-25^{\circ}, 25^{\circ}, 50^{\circ}, 75^{\circ}, 90^{\circ}\right.$, and $\left.180^{\circ}\right)$. On each trial, the circle containing either the vertical $\left(90^{\circ}\right)$ or horizontal $\left(180^{\circ}\right)$ line segment represented the target. The position of the target relative to the critical object varied across trials, with their spatial locations matched on $1 / 6$ of trials, and mismatched on $5 / 6$ of trials. This was done to ensure that the critical object (food or instrument) was not associated with the target in such a way that participants could predict the location of the target based on the location of the critical object, in accordance with the paradigm developed by Devue et al. (2012). The number of times an object (target, critical object, or filler object) appeared at a given location in the array was equally distributed across the six possible locations. An illustration of the display for each trial type is depicted in Fig. 1.

\subsubsection{Task for participant}

Participants completed the task individually, seated at a computer featuring a 17-inch monitor.

Each participant was required to determine as quickly and accurately as possible whether the target was a horizontal or a vertical line. Responses were recorded using a response pad featuring buttons corresponding to a horizontal line and a vertical line respectively. The participant was told that the pictures on the screen were irrelevant to the task and should be ignored. The dependent variables of interest were response latency and accuracy on the four trial types (i.e., 48 foodmatch trials, 240 food-mismatch trials, 48 instrument-match trials, and 240 instrument-mismatch trials). The search display was presented on the screen until the participant made a response. Participants were instructed to respond more quickly if they took more than $4000 \mathrm{~ms}$ to respond on the previous trial. A fixation cross was presented for $600 \mathrm{~ms}$ between trials. Prior to the start of the attention task, the participant completed 24 practice trials to familiarize herself with the task. The practice trials were identical to the experimental trials with the exception that the images displayed with the array of grey circles were randomly selected from a directory of animals. The experimental portion of the task included 576 trials (4 blocks of 144 trials), with mood booster sessions occurring in between blocks.

\subsection{Experimental procedure}

Eligible participants were invited to the laboratory to complete the experiment. Participants were instructed to avoid eating within $2 \mathrm{~h}$ prior to the start of the experiment, and compliance with this instruction was documented before the experiment proceeded. A demographics questionnaire was first administered, after which the participant rated her mood and hunger on $100 \mathrm{~mm}$ VAS. The participant then underwent their assigned mood manipulation. State mood was measured again directly after the mood induction. The participant was then seated at a desk with their faces approximately $50 \mathrm{~cm}$ away from a PC monitor to complete the attention task. When the task was finished, the participant was asked to describe her predictions about the purpose of the experiment to ascertain whether the cover story had been effective. Following this, the participant underwent a positive mood induction regardless of her assigned mood condition. A five-minute video about 
A
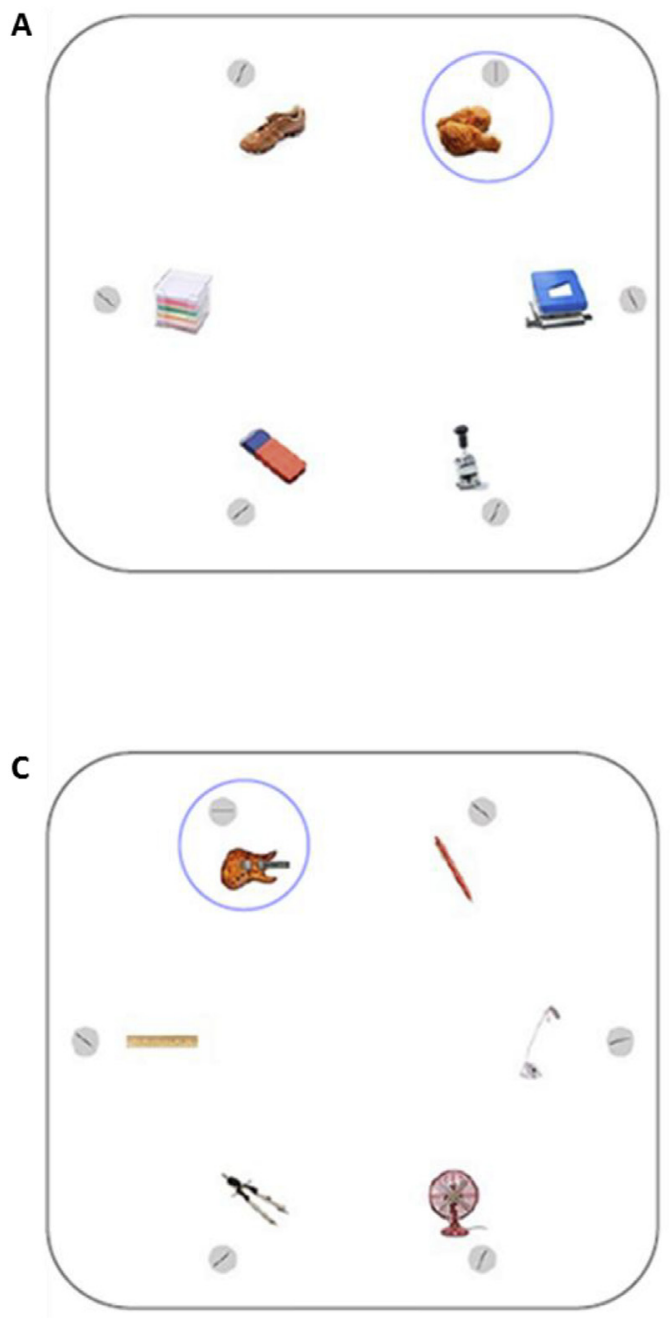

B

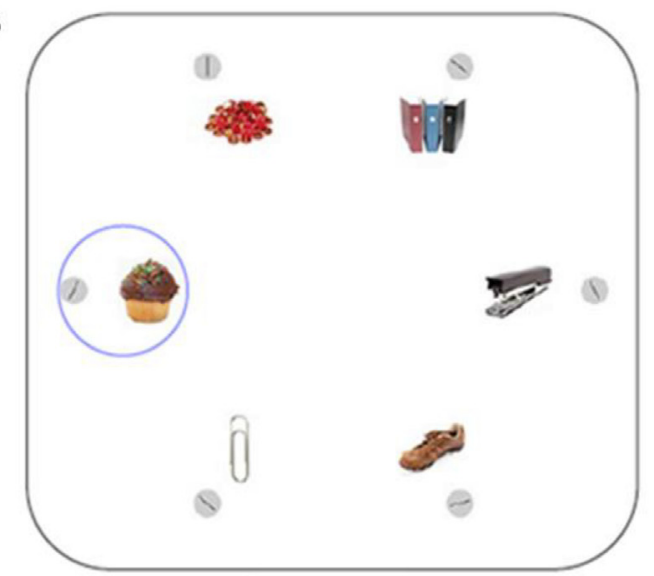

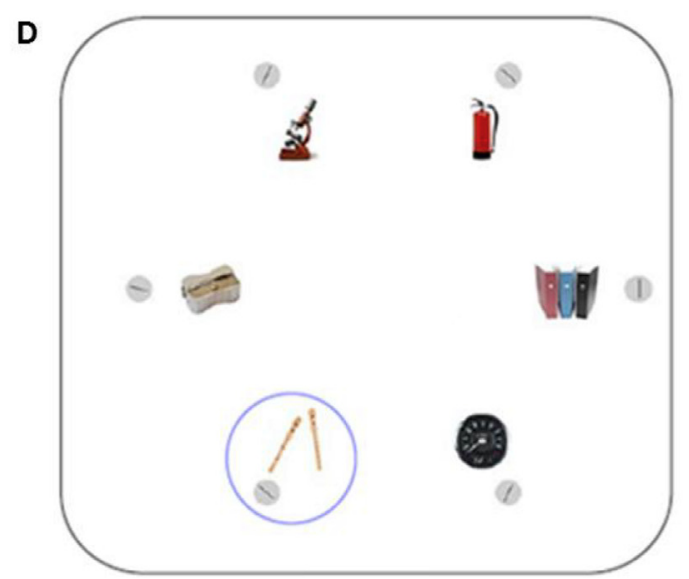

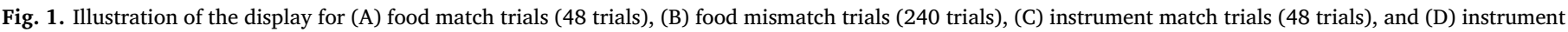
mismatch trials (240 trials).

the effect of playing an instrument on the brain was then presented as a distractor task to minimize the effects of the mood manipulations on the participant's responses on questionnaires. Finally, the participant completed the Restraint Scale and BDI and had their height and weight measured.

\subsection{Statistical approach}

To test the primary study hypotheses, two 2 (Condition: neutral vs. negative mood) $\times 2$ (Critical object: food vs. neutral) $\times 2$ (Target location: match vs. mismatch) mixed ANOCVAs with dietary restraint included as a mean-centered continuous covariate were conducted to predict response latency and response accuracy respectively. Condition was entered as the between-subjects factor, while response latency and accuracy were dependent variables. Attentional bias for food was operationalized as more speeded responding on trials in which the target was displayed adjacent to an image of food and/or slowed responding on trials in which the target was displayed adjacent to an instrument. Significant Critical object $\times$ Target location interactions were considered to be evidence of attentional bias toward food. Interactions with the dietary restraint covariate were included using the custom model option in SPSS (version 24, IBM corp., Armonk, NY).

\section{Results}

\subsection{Participants}

A total of 100 female university students participated in all experimental procedures. However, participants $(n=4)$ whose response accuracy fell below $70 \%$ of trials ( $>3$ SD from the mean) were excluded from all analyses given the possibility that these participants were not exerting adequate effort during the task. Of these remaining participants, 47 had been randomized to the neutral mood condition, while 49 had been randomized to the negative mood condition. No participant characteristics at baseline were significantly predictive of mood condition membership (Table 1 ). ${ }^{1}$

\footnotetext{
${ }^{1}$ Participants were drawn from a student population and were not evaluated for the presence of an eating disorder. BMI was calculated following the completion of the experiment when all data had been collected and entered. Mean sample BMI $\mathrm{kg} / \mathrm{m}^{2}$ was $22.52(S D=3.78$, range $=16.4-37.8)$, with two participants having a BMI below the 17.5 cutoff in the diagnostic criteria for Anorexia Nervosa. When dietary restraint was retained in the model, removal of these two participants caused the interaction between mood condition, critical object, and target location to become marginally significant $(F(1,92)=3.844$, $p=0.053$ ), though the direction of the effect was maintained. When dietary restraint was removed from the model given its lack of an effect, the relationship between mood condition, critical object, and target location remained significant $(F(1,92)=3.992, p=0.049)$ after excluding underweight
} 
Table 1

Sample demographic characteristics.

\begin{tabular}{|c|c|c|c|c|}
\hline & Neutral $(n=47)$ & Negative $(n=49)$ & Total $(n=96)$ & Group differences \\
\hline & Mean $(S D)$ & Mean $(S D)$ & Mean $(S D)$ & $t(94)(p-v a l u e)$ \\
\hline Age (years) & 21.57 (2.59) & $20.76(2.50)$ & $21.16(2.56)$ & $-1.577(0.12)$ \\
\hline BMI $\left(\mathrm{kg} / \mathrm{m}^{2}\right)$ & $22.52(3.78)$ & $22.54(2.63)$ & $22.53(3.23)$ & $0.032(0.97)$ \\
\hline Time since last meal (hours) & $4.25(4.19)$ & $4.93(4.50)$ & $4.60(4.34)$ & $0.774(0.44)$ \\
\hline Hunger & $43.45(27.84)$ & $42.51(26.49)$ & $42.97(27.02)$ & $-0.169(0.87)$ \\
\hline Desire to eat & $43.36(29.48)$ & $41.31(27.97)$ & $42.31(28.58)$ & $-0.351(0.73)$ \\
\hline Dietary Restraint & $12.81(4.51)$ & $13.84(4.96)$ & $13.33(4.75)$ & $1.060(0.29)$ \\
\hline Emotion Suppression & $12.60(3.82)$ & $11.96(4.06)$ & $12.27(3.94)$ & $-0.791(0.43)$ \\
\hline Emotion Reappraisal & $29.57(4.96)$ & $29.14(5.80)$ & $29.35(5.38)$ & $-0.391(0.69)$ \\
\hline \multirow[t]{2}{*}{ BDI } & $8.18(6.08)$ & $7.72(6.01)$ & $7.95(6.02)$ & $-0.987(0.72)$ \\
\hline & $n(\%)$ & $n(\%)$ & $n(\%)$ & $X^{2}(p$-value $)$ \\
\hline Guessed study purpose & $12(25.2)$ & $7(14.3)$ & $19(19.8)$ & $1.911(0.21)$ \\
\hline English Questionnaires & $36(76.6)$ & $30(61.2)$ & $66(68.8)$ & $2.638(0.13)$ \\
\hline
\end{tabular}

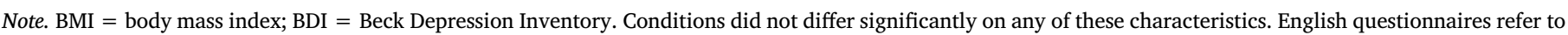
the number of participants who elected to complete their questionnaires in English as opposed to Dutch.

Table 2

Average sadness and happiness ratings by mood condition and time.

\begin{tabular}{|c|c|c|c|c|c|c|}
\hline & \multicolumn{3}{|l|}{ Sad VAS } & \multicolumn{3}{|l|}{ Happy VAS } \\
\hline & Neutral $M(S D)$ & Negative $M(S D)$ & $t(94)$ & Neutral $M(S D)$ & Negative $M(S D)$ & $t(94)$ \\
\hline Baseline & $17.04(17.08)$ & $14.61(12.82)$ & -0.79 & $59.70(12.43)$ & 65.47 (14.55) & $2.08 *$ \\
\hline Post-induction 1 & $19.51(16.75)$ & $55.65(17.74)$ & $10.25^{* *}$ & $60.13(18.45)$ & $37.92(18.10)$ & $-5.95^{* *}$ \\
\hline Post-induction 2 & $21.02(17.23)$ & $47.94(27.86)$ & $5.66^{* *}$ & 55.19 (19.03) & $36.22(25.74)$ & $-4.09^{* *}$ \\
\hline Post-induction 3 & $19.85(17.47)$ & $46.49(28.85)$ & $5.45^{* *}$ & $53.89(20.03)$ & $34.63(26.46)$ & $-4.01 * *$ \\
\hline Post-induction 4 & $20.91(18.44)$ & $50.67(20.73)$ & $7.42^{* *}$ & $53.91(20.65)$ & 37.24 (19.57) & $-4.06^{* *}$ \\
\hline
\end{tabular}

Note. VAS = visual analog scale.

${ }^{*} p<0.05$.

$* * p<0.01$.

\subsection{Manipulation check}

Participants' descriptions of the study purpose were rated as accurate if they mentioned food, the relationship between food and mood, or attention to food. Based on these criteria, $20 \%$ of participants were rated as having accurately guessed the purpose of the study. Baseline ratings of sadness predicted accuracy of guess, such that individuals with higher baseline sadness ratings were more likely to guess the purpose of the study $(t(94)=3.310, p<0.01)$. There were no other significant predictors of accuracy of guess.

To determine whether the mood manipulation was effective, a 2 (Condition: neutral vs. negative mood) $\times 5$ (Time: baseline, post-manipulation, post-mood boost 1 , post-mood boost 2 , and final VAS measurement) mixed model repeated measures ANOVA was conducted. Analyses confirmed that the mood manipulation was effective, with there being a significant condition $\times$ time interaction for both sadness $(F(4,91)=28.573, p<0.01)$ and happiness ratings $(F \quad(4$, $91)=21.850, p<0.01)$. Table 2 includes a more detailed description of mood ratings by condition.

\subsection{Data cleaning}

Prior to performing statistical tests, data from the attention task were inspected for outliers. Trials on which response latency was below $200 \mathrm{~ms}$ or greater than $3500 \mathrm{~ms}$ ( $>$ 3SD from sample mean) were removed. This resulted in the exclusion of 257 trials summed over all participants $(0.4 \%$ of all trials $)$.

(footnote continued)

participants.

\subsection{Effects of mood state and restrained eating on attentional bias for food}

Although we proposed to compute attentional bias scores within a regression framework in our AsPredicted registration, we instead opted to conduct repeated measures ANCOVAs with response latency and accuracy as dependent variables. We did so because performance on the match trials was unexpectedly slower than on mismatch trials (see Fig. 2), which is not consistent with the original research using this paradigm (Devue et al., 2012). The use of bias scores would obscure this important and unexpected aspect of the data. The reported analyses are more transparent about the nature of the results.

\subsubsection{Response latency}

Contrary to predictions, there was no evidence of a significant Dietary Restraint $\times$ Mood condition $\times$ Critical object $\times$ Target location interaction $(F(1,92)=0.002, p=0.96)$. The 3 -way interaction between dietary restraint, critical object, and target location was also not significant $(F(1,92)=2.214, p=0.14)$. Similarly, there was no interaction between dietary restraint and critical object type $(F(1$, $92)=1.726, p=0.19)$ or target location $(F(1,92)=0.051, p=0.82)$, nor was there a main effect of dietary restraint $(F(1,92)=0.008$, $p=0.93)$. The Dietary restraint $\times$ Mood condition interaction term was then removed from the model. Again, neither the Dietary restraint $\times$ Critical object type $(F(1,92)=1.974, p=0.16)$ or Dietary restraint $\times$ Target location $(F(1,92)=0.028, p=0.87)$ interaction terms were significant, nor was there a main effect of dietary restraint $(F(1,92)=0.052, p=0.82)$. However, the Mood condition $\times$ Critical object $\times$ Target location interaction term was significant $(F$ (1, $92)=4.063, p=0.047)^{2}$. Given that dietary restraint was not associated with task performance, it was removed from subsequent models. 


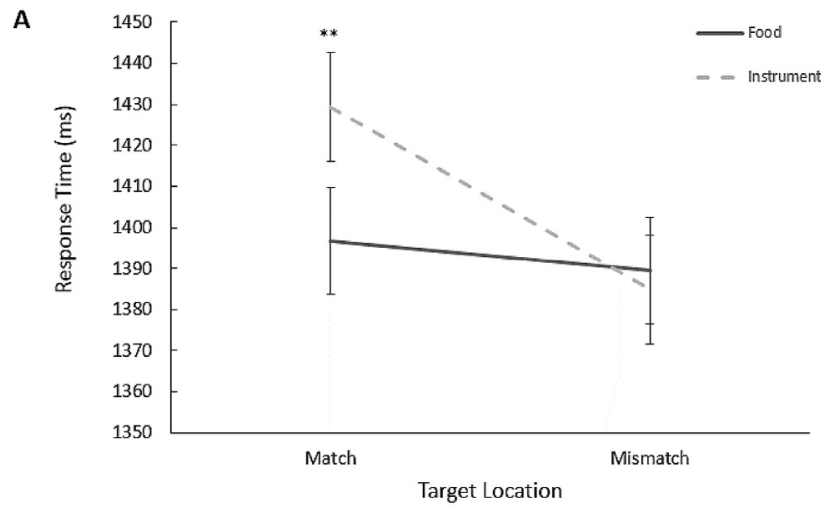

B

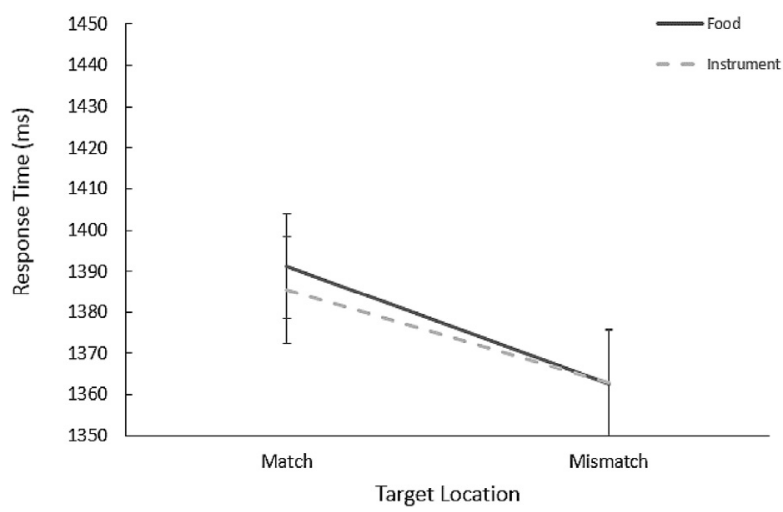

Fig. 2. Mean response time by trial type for (A) the neutral mood condition and (B) the negative mood condition. Error bars reflect \pm 1 standard error. **p $<0.01$.

The 3-way interaction between mood condition, critical object, and target location remained significant $(F(1,92)=4.737, p=0.032$; see Fig. 2).

To further examine this 3-way interaction, two 2 (Critical object) $\times 2$ (Target location) ANOVAs were performed separately for each mood condition. Among individuals in the neutral mood condition, the Critical object $\times$ Target location interaction was significant $(F(1$, $46)=7.723, p<0.01)$, qualifying main effects of both critical object $(F(1,46)=5.071, p=0.03)$ and target location $(F(1,46)=12.415$, $p<0.01)$. In the negative mood condition, the Critical object $\times$ Target location interaction did not reach significance $(F(1,48)=0.067$, $p=0.80)$. Only a main effect of target location reached significance $(F$ $(1,48)=9.382, p<0.01)$

To further explore the Critical object $\times$ Target location interaction in the neutral mood condition, paired-samples t-tests were conducted. These analyses revealed that response latency on instrument match trials was significantly greater than on food match trials $(t(46)=4.263$, $p<0.01$ ), whereas the difference between food versus instrument mismatch trials was not significant $(t(46)=0.782, p=0.44)$.

Note that regardless of dietary restraint, mood condition, and critical object type (food vs. instrument), performance on mismatch trials was not significantly different from performance on match trials $(F(1$, $92)=1.873, p=0.17)$. Collapsing across critical object type, the overall sample mean reaction time on mismatch trials was $1374.71 \mathrm{~ms}$, compared to a mean reaction time of $1400.42 \mathrm{~ms}$ on match trials $(t$ $(95)=4.639, p<0.01)$. This observation was unexpected based on

\footnotetext{
${ }^{2}$ Removal of individuals ( $n=20$ ) who accurately guessed the purpose of the study caused the interaction between mood condition, critical object, and target location to become marginally significant $(F(2,74)=2.882, p=0.06)$. This is likely due to the large reduction in sample size. Otherwise, the results remained the same.
}

previous research, including that by Devue et al. (2012). One possible explanation for this finding is that participants learned to expect the target at the location of the filler (i.e., mismatch) objects because this trial type occurred most frequently, and filler objects tended to belong to the same category (i.e., office objects). To test this hypothesis, a posthoc 2 (Mood condition) $\times 4$ (Block) $\times 2$ (Critical object) $\times 2$ (target location) mixed model repeated measures ANCOVA was conducted, with dietary restraint entered as a covariate. This analysis revealed that response latency decreased over the course of the experimental task ( $F$ $(1,92)=221.132, p<0.01)$, but that the extent of this decrease did not differ by critical object $(F(1,92)=0.717, p=0.40)$, by target location $(F(1,92)=0.372, p=0.54)$, mood condition $(F(1$, $92)=0.177, p=0.68)$, or dietary restraint $(F(1,92)=0.274$, $p=0.60$ ). Superior performance on mismatch trials compared to match trials was evident as early as the first block of the task, which is inconsistent with there being a learning effect.

\subsubsection{Response accuracy}

There was no evidence of a 4-way interaction between dietary restraint, mood condition, critical object, and target location ( $F$ (1, $92)=1.040, p=0.31)$. Further, there was no significant main effect of dietary restraint $(F(1,92)=0.000, p=0.99)$ or mood condition $(F(1$, $92)=0.028, p=0.87)$ on response accuracy. Mean percentage of errors on each trial type are listed in Table 3.

\section{Discussion}

The present study examined whether experimentally induced negative mood moderates the relationship between dietary restraint and attentional processing of food cues. This is motivated by the fact that dietary restraint has not been consistently linked to attentional bias for food cues (Werthmann et al., 2015), suggesting that such a relationship may only emerge in specific contexts, such as during the experience of a negative mood. It was predicted that dietary restraint would be associated with biased attention to food cues among individuals in a negative mood state but not among individuals in a neutral mood. However, there was no evidence to support this hypothesis. Further, although the negative mood induction produced the desired changes in mood state, mood condition did not significantly moderate the effect of dietary restraint on the allocation of attention toward food. The absence of an effect of dietary restraint is consistent with several investigations of attentional processing of food among chronic dieters (Boon et al., 2000; Forestell et al., 2012; Hollitt et al., 2010; Veenstra et al., 2010; Veenstra \& de Jong, 2012; Werthmann et al., 2013; Wilson \& Wallis, 2013). It is possible that attentional bias toward food cues is not a central feature of dietary restraint, at least as it has been assessed in the current study. Alternatively, a relationship between dietary restraint and attentional bias toward food cues may only emerge in the presence of specific contextual factors that were not tested in the present study (e.g., activation or suppression of health and weight goals, Werthmann, Jansen, \& Roefs, 2016). It will be important to further investigate the

Table 3

Average percentage of errors made by trial type, dietary restraint, and mood condition.

\begin{tabular}{lllll}
\hline & \multicolumn{2}{l}{ Low Restraint } & \multicolumn{2}{l}{ High Restraint } \\
\cline { 2 - 5 } & Neutral & Negative & Neutral & \multirow{2}{*}{ Negative } \\
\hline Food match trials & $5.25 \%$ & $5.61 \%$ & $4.48 \%$ & $4.89 \%$ \\
Food mismatch trials & $4.86 \%$ & $5.32 \%$ & $3.75 \%$ & $4.98 \%$ \\
Instrument match trials & $5.02 \%$ & $5.93 \%$ & $4.27 \%$ & $3.89 \%$ \\
Instrument mismatch trials & $4.71 \%$ & $5.26 \%$ & $3.73 \%$ & $4.89 \%$ \\
\hline
\end{tabular}

Note. For illustrative purposes, individuals were categorized as either high or low in dietary restraint using the median split of dietary restraint scores. However, dietary restraint was used as a continuous variable in all analyses. 
conditions under which attentional processing of food cues is enhanced or diminished among chronic dieters, as this information will be valuable for the development of new approaches to treating problem eating and weight gain in this population.

Although data did not support the hypothesized interaction between dietary restraint and mood condition, results demonstrated that there was a significant effect of mood condition on attentional processing of food. Among individuals in the neutral mood condition, response latency was significantly shorter on food match trials compared to instrument match trials, a difference in performance not evident on mismatch trials. This finding is suggestive of attentional bias for food in the neutral mood condition. No such effect was observed in the negative mood condition, in which performance on mismatch trials was superior to match trials regardless of which critical object was present. Note though that the interpretation of attentional bias for food in the neutral mood condition is complicated by the fact that the average response latency on the food match trials was not faster than on the mismatch trials (food and instrument). The effect on the match trials in the neutral mood condition seems to be due to a slower response on the instrument match trials relative to the food match trials.

This complicated pattern of results may partly be explained by the unanticipated advantage on the mismatch trials. Participants may have been primed to be thinking about and attending to information related to music, given that the cover story for the experiment and several of the experimental tasks were focused on music and the effects of music on cognition. As a consequence of such priming, participants' performance on instrument trials may have been affected in ways that it would not have otherwise if instruments were not used as the comparison object category. Future studies should take care to construct a cover story entirely irrelevant to the objects presented during the visual search task, and consider modifying the task so that the filler objects presented on each trial are drawn from distinct categories. It will be important to use and adapt the task used in the present study to establish its reliability and validity as a measure of food-related attentional bias.

The lack of a specific effect of negative mood on attentional processing of food, while not in line with our hypothesis, is consistent with a recent study demonstrating that individuals in a neutral mood preferentially oriented their attention toward food cues compared to those who had undergone a negative mood induction (Werthmann et al., 2014b). Another study found that induced sadness was associated with less rather than more interference on a standard flanker task, indicating that individuals who were experiencing sadness were better able to ignore irrelevant information compared to individuals in a neutral mood (Bellaera \& von Mühlenen, 2017). These findings may help to clarify why the presence of food did not affect performance among individuals in the negative mood condition as expected. It is possible that those in the negative mood condition more successfully focused their attention on the target, filtering out the images that were not relevant to the stated purpose of the task.

There are several limitations of the present study that should be considered when interpreting the results and addressed in future research. First, the filler objects used as distractors in the experimental task tended to belong to a single object category. It would be preferable for these objects to be drawn from many distinct categories to limit the ability of participants to learn that it is advantageous to focus their attention on filler objects as opposed to the critical objects of interest. Although we did not find evidence to support a learning effect, it is not possible to determine with certainty that this unintended feature of the task did not influence participants' performance. Second, $20 \%$ of participants were able to discern the purpose of the study despite experimenter attempts to conceal it, which may have influenced their approach to the attention task. Given that the mood groups did not differ significantly in the number of individuals who guessed the study purpose, it is not likely that this accounts for the observed effect of mood group. However, it does suggest that the cover story was not fully effective. It will be important to construct a cover story that is less closely related to the objects being presented in the task while still maintaining plausibility. Third, it is possible that the lack of an effect of self-reported dietary restraint on attention allocation may be related to the selection of instrument to assess restraint. Although the Restraint Scale captures eating behaviors most theoretically relevant to the present study question (e.g., disinhibited eating), it may have been valuable to assess of other features of dietary restraint not adequately captured by the Restraint Sale. Doing so would have permitted quantitative evaluation of how these somewhat distinct features relate to attentional processing of food cues under various mood conditions. Fourth, the food images presented to participants were not tailored to their individual preferences. Customizing which foods were presented may have yielded more robust effects.

Overall, the present study suggests that mood state may influence the allocation of attention to food cues, though unexpectedly this effect occurred in a neutral mood state. As such, the results of the present study do not shed any additional light on the mechanisms linking depressed mood and problem eating. It would be interesting to replicate this study using eye-tracking to determine whether the induction of a negative mood does indeed lead to more focused attention toward target stimuli, limiting the influence of irrelevant food cues on attention. Should it be determined that negative mood does lead to reduced distractibility, this would help to clarify the surprising observation that individuals in a negative mood state did not exhibit differences in performance on food trials compared to neutral trials, while individuals in a neutral mood state did. It will also be necessary to modify the task design to address the issues noted above.

\section{Declaration of interest}

The authors report no conflicts of interest. This research was supported by NSF Graduate Research Opportunities Worldwide (GROW) fellowship number DGE 124-7842 (SDD) jointly funded by the NSF (USA) and NWO (the Netherlands). The funding sources had no involvement in the study design, the collection, analysis, or interpretation of data, in the writing of the manuscript, or in the decision to submit the manuscript for publication.

\section{References}

Ahern, A. L., Field, M., Yokum, S., Bohon, C., \& Stice, E. (2010). Relation of dietary restraint scores to cognitive biases and reward sensitivity. Appetite, 55, 61-68. https://doi.org/10.1016/j.appet.2010.04.001.

Anderson, C. B., \& Bulik, C. M. (2004). Gender differences in compensatory behaviors, weight and shape salience, and drive for thinness. Eating Behaviors, 5, 1-11. https:// doi.org/10.1016/j.eatbeh.2003.07.001.

Baucom, D. H., \& Aiken, P. A. (1981). Effect of depressed mood on eating among obese and nonobese dieting and nondieting persons. Journal of Personality and Social Psychology, 41, 577-585.

Beck, A. T., Steer, R. A., Ball, R., \& Ranieri, W. F. (1996). Comparison of Beck depression inventories-IA and-II in psychiatric outpatients. Journal of Personality Assessment, 67, 588-597. https://doi.org/10.1207/s15327752jpa6703 13.

Bellaera, L., \& von Mühlenen, A. (2017). The effect of induced sadness and moderate depression on attention networks. Cognition \& Emotion, 1-13. https://doi.org/10. 1080/02699931.2016.1197101.

Bohon, C., \& Stice, E. (2012). Negative affect and neural response to palatable food intake in bulimia nervosa. Appetite, 58, 964-970. https://doi.org/10.1016/j.appet.2012.02. 051.

Bohon, C., Stice, E., \& Spoor, S. (2009). Female emotional eaters show abnormalities in consummatory and anticipatory food reward: A functional magnetic resonance imaging study. International Journal of Eating Disorders, 42, 210-221. https://doi.org/ 10.1002/eat.20615.

Boon, B., Vogelzang, L., \& Jansen, A. (2000). Do restrained eaters show attention toward or away from food, shape and weight stimuli? European Eating Disorders Review, 8, 51-58.

Brownell, K. D., \& Horgen, K. B. (2004). Food fight: The inside story of the food industry, America's obesity crisis, and what we can do about it. Chicago, IL: Contemporary books.

Cardi, V., Leppanen, J., \& Treasure, J. (2015). The effects of negative and positive mood induction on eating behaviour: A meta-analysis of laboratory studies in the healthy population and eating and weight disorders. Neuroscience \& Biobehavioral Reviews, 57, 299-309. https://doi.org/10.1016/j.neubiorev.2015.08.011.

Chua, J. L., Touyz, S., \& Hill, A. J. (2004). Negative mood-induced overeating in obese 
binge eaters: An experimental study. International Journal of Obesity, 28, 606-610.

Crosby, R. D., Wonderlich, S. A., Engel, S. C., Simonich, H., Smyth, J., \& Mitchell, J. E. (2009). Daily mood patterns and bulimic behaviors in the natural environment. Behavior Research and Therapy, 47, 181-188. https://doi.org/10.1016/j.brat.2008. 11.006.

Davy, S. R., Benes, B. A., \& Driskell, J. A. (2006). Sex differences in dieting trends, eating habits, and nutrition beliefs of a group of midwestern college students. Journal of the American Dietetic Association, 106, 1673-1677. https://doi.org/10.1016/j.jada.2006. 07.017.

Devue, C., Belopolsky, A. V., \& Theeuwes, J. (2012). Oculomotor guidance and capture by irrelevant faces. PloS One, 7, e34598. https://doi.org/10.1371/journal.pone. 0034598.

Fay, S. H., \& Finlayson, G. (2011). Negative affect-induced food intake in non-dieting women is reward driven and associated with restrained-disinhibited eating subtype. Appetite, 56, 682-688. https://doi.org/10.1016/j.appet.2011.02.004.

Field, A. E., Austin, S. B., Taylor, C. B., Malspeis, S., Rosner, B., Rockett, H. R., et al (2003). Relation between dieting and weight change among preadolescents and adolescents. Pediatrics, 112, 900-906.

Forestell, C. A., Lau, P., Gyurovski, I. I., Dickter, C. L., \& Haque, S. S. (2012). Attentional biases to foods: The effects of caloric content and cognitive restraint. Appetite, 59, 748-754. https://doi.org/10.1016/j.appet.2012.07.006.

Haedt-Matt, A. A., \& Keel, P. K. (2011). Revisiting the affect regulation model of binge eating: A meta-analysis of studies using ecological momentary assessment. Psychological Bulletin, 137, 660-681. https://doi.org/10.1037/a0023660.

Harris, J. L., Bargh, J. A., \& Brownell, K. D. (2009). Priming effects of television food advertising on eating behavior. Health Psychology, 28, 404-413 10.1037.

Heatherton, T. F., Herman, C. P., \& Polivy, J. (1991). Effects of physical threat and ego threat on eating behavior. Journal of Personality and Social Psychology, 60, 1380-2143. https://doi.org/10.1037/0022-3514.60.1.138.

Heatherton, T. F., \& Wagner, D. D. (2011). Cognitive neuroscience of self-regulation failure. Trends in Cognitive Sciences, 15, 132-139. https://doi.org/10.1016/j.tics. 2010.12.005.

Hepworth, R., Mogg, K., Brignell, C., \& Bradley, B. P. (2010). Negative mood increases selective attention to food cues and subjective appetite. Appetite, 54, 134-142. https://doi.org/10.1016/j.appet.2009.09.019.

Herman, C. P., \& Polivy, J. (1975). Anxiety, restraint, and eating behavior. Journal of Abnormal Psychology, 84, 666-672. https://doi.org/10.1037/0021-843X.84.6.666.

Herman, C. P., Polivy, J., Pilner, P., Threlkeld, J., \& Munic, D. (1978). Distractibility in dieters and nondieters: An alternative view of "externality". Journal of Personality and Social Psychology, 36, 536-548. https://doi.org/10.1037/0022-3514.36.5.536.

Hollitt, S., Kemps, E., Tiggemann, M., Smeets, E., \& Mills, J. S. (2010). Components of attentional bias for food cues among restrained eaters. Appetite, 54, 309-313. https:// doi.org/10.1016/j.appet.2009.12.005.

Jansen, A., Nederkoorn, C., can Baak, L., Keirse, C., Guerrieri, R., \& Havermans, R. (2009). High-restrained eaters only overeat when they are also impulsive. Behaviour Research and Therapy, 47, 105-110. https://doi.org/10.1016/j.brat.2008.10.016.

Jansen, A., Oosterlaan, J., Merckelbach, H., \& van den Hout, M. (1988). Nonregulation of food intake in restrained, emotional, and external eaters. Journal of Psychopathology and Behavioral Assessment, 10, 345-354.

Jansen, A., Vanreyten, A., van Balveren, T., Roefs, A., \& Nederkoorn, C. (2008). Negative affect and cue-induced overeating in non-eating disordered obesity. Appetite, 51, 556-562. https://doi.org/10.1016/j.appet.2008.04.009.

Laessle, R. G., Tuschl, R. J., Kotthaus, B. C., \& Prike, K. M. (1989). A comparison of the validity of three scales for the assessment of dietary restraint. Journal of Abnormal Psychology, 98, 504-507. https://doi.org/10.1037/0021-843X.98.4.504.

Lowe, M. R., Annunziato, R. A., Markowitz, J. T., Didie, E., Bellace, D. L., Riddell, L., ... Stice, E. (2006). Multiple types of dieting prospectively predict weight gain during the freshman year of college. Appetite, 47, 83-90.

Meule, A., Vögele, C., \& Kübler, A. (2012). Restrained eating is related to accelerated reaction to high caloric foods and cardiac autonomic dysregulation. Appetite, 58, 638-644. https://doi.org/10.1016/j.appet.2011.11.023.

Mills, J. S., Weinheimer, L. A., Polivy, J., \& Herman, C. P. (2018). Are there different types of dieters? A review of personality and dietary restraint. Appetite, 125, 380-400. https://doi.org/10.1016/j.appet.2018.02.014.
Neimeijer, R. A., de Jong, P. J., \& Roefs, A. (2013). Temporal attention for visual food stimuli in restrained eaters. Appetite, 64, 5-11. https://doi.org/10.1016/j.appet. 2012.12.013.

Papies, E. K., \& Hamstra, P. (2010). Goal priming and eating behavior: Enhancing selfregulation by environmental cues. Health Psychology, 29, 384-388. https://doi.org/ $10.1037 / \mathrm{a} 0019877$.

Stice, E., Cameron, R. P., Killen, J. D., Hayward, C., \& Taylor, C. B. (1999). Naturalistic weight reduction efforts prospectively predict growth in relative weight and onset of obesity among female adolescents. Journal of Consulting and Clinical Psychology, 67, 967-974.

Stroebe, W., Van Koningsbruggen, G. M., Papies, E. K., \& Aarts, H. (2013). Why most dieters fail but some succeed: A goal conflict model of eating behavior. Psychological Review, 120, 110-138. https://doi.org/10.1037/a0030849.

Van Strien, T., Frijters, J. E., Bergers, G., \& Defares, P. B. (1986). The Dutch Eating Behavior Questionnaire (DEBQ) for assessment of restrained, emotional, and external eating behavior. International Journal of Eating Disorders, 5, 295-315.

Veenstra, E. M., \& de Jong, P. J. (2012). Attentional bias in restrictive eating disorders. Stronger attentional avoidance of high-fat food compared to healthy controls? Appetite, 58, 133-140. https://doi.org/10.1016/j.appet.2011.09.014.

Veenstra, E. M., de Jong, P. J., Koster, E. H., \& Roefs, A. (2010). Attentional avoidance of high fat food in unsuccessful dieters. Journal of Behavior Therapy and Experimental Psychiatry, 41, 282-288. https://doi.org/10.1016/j.jbtep.2010.02.006.

Vuoskoski, J. K., \& Eerola, T. (2012). Can sad music really make you sad? Indirect measures of affective states induced by music and autobiographical memories. Psychology of Aesthetics, Creativity, and the Arts, 6, 204-213. https://doi.org/10.1037/ a0026937.

Wagner, D. D., Boswell, R. G., Kelley, W. M., \& Heatherton, T. F. (2012). Inducing negative affect increases the reward value of appetizing foods in dieters. Journal of Cognitive Neuroscience, 24, 1625-1633. https://doi.org/10.1162/jocn_a_00238.

Werthmann, J., Field, M., Roefs, A., Nederkoorn, C., \& Jansen, A. (2014a). Attention bias for chocolate increases chocolate consumption-An attention bias modification study. Journal of Behavior Therapy and Experimental Psychiatry, 45, 136-143. https://doi. org/10.1016/j.jbtep.2013.09.009.

Werthmann, J., Jansen, A., \& Roefs, A. (2015). Worry or craving? A selective review of evidence for food-related attention biases in obese individuals, eating-disorder patients, restrained eaters and healthy samples. Proceedings of the Nutrition Society, 74 99-114. https://doi.org/10.1017/S0029665114001451.

Werthmann, J., Jansen, A., \& Roefs, A. (2016). Make up your mind about food: A healthy mindset attenuates attention for high-calorie food in restrained eaters. Appetite, 105, 53-59. https://doi.org/10.1016/j.appet.2016.05.005.

Werthmann, J., Renner, F., Roefs, A., Huibers, M., Plumanns, L., Krott, N., et al. (2014b). Looking at food in sad mood: Do attention biases lead emotional eaters into overeating after negative mood induction? Eating Behaviors, 15, 230-236. https://doi.org/ 10.1016/j.eatbeh.2014.02.001.

Werthmann, J., Roefs, A., Nederkoorn, C., Mogg, K., Bradley, B. P., \& Jansen, A. (2011). Can (not) take my eyes off it: Attention bias for food in overweight participants. Health Psychology, 30, 561-569.

Werthmann, J., Roefs, A., Nederkoorn, C., Mogg, K., Bradley, B. P., \& Jansen, A. (2013) Attention bias for food is independent of restraint in healthy weight individuals-an eye tracking study. Eating Behaviors, 14, 397-400. https://doi.org/10.1016/j.eatbeh. 2013.06.005.

Williamson, D. A., Martin, C. K., York-Crowe, E., Anton, S. D., Redman, L. M., Han, H., et al. (2007). Measurement of dietary restraint: Validity tests of four questionnaires. Appetite, 48, 183-192.

Willner, P., Benton, D., Brown, E., Cheeta, S., Davies, G., Morgan, J., et al. (1998). "Depression" increases "craving" for sweet rewards in animal and human models of depression and craving. Psychopharmacology, 136, 272-283. https://doi.org/10. $1007 / \mathrm{s} 002130050566$.

Wilson, C., \& Wallis, D. J. (2013). Attentional bias and slowed disengagement from food and stimuli in restrained eaters using a modified Stroop task. Cognitive Therapy and Research, 37, 127-138. https://doi.org/10.1007/s10608-012-9451-x.

Yokum, S., Ng, J., \& Stice, E. (2011). Attentional bias to food images associated with elevated weight and future weight gain: An fMRI study. Obesity, 19, 1775-1783. https://doi.org/10.1038/oby.2011.168. 